Revista Brasileira de Cartografia

ISSN 1808-0936 | https://doi.org/10.14393/revbrascartogr

Sociedade Brasileira de Cartografia, Geodésia, Fotogrametria e Sensoriamento Remoto

\title{
Cadastro Marinho no Atlântico Sul: evolução, situação e perspectivas
}

\section{Marine Cadastre in the South Atlantic: evolution, situation and perspectives}

\author{
Luiz Fernando Palin Droubi ${ }^{1}$, Ramiro Alberdi ${ }^{2}$, Diego Alfonso Erba ${ }^{3}$ e Everton da Silva ${ }^{4}$
}

1 Secretaria de Coordenação e Governança do Patrimônio da União, SPU/SC, Florianópolis, Brasil. lfpdroubi@gmail.com ORCID: https://orcid.org/0000-0002-5971-7220

2 Universidad Nacional del Litoral, Facultad de Ingeniería y Ciencias Hídricas, Santa Fe, Argentina. ralberdi@fich.unl.edu.ar ORCID: https://orcid.org/0000-0002-2734-5573

3 Coordenador da Red Académica de Catastro Mulfinalitario - RACAM, Pereira, Colômbia. diegoerba@gmail.com ORCID: https://orcid.org/0000-0003-1222-1401

4 Universidade Federal de Santa Catarina, Departamento de Geociências - GCN, Florianópolis, Brasil. everton.silva@ufsc.br ORCID: https://orcid.org/0000-0001-9724-8384

Resumo: O cadastro é a base do sistema de administração territorial de um país, contém o registro dos distintos interesses sobre o território nacional, descreve geometricamente os imóveis e interopera com outros registros. Normalmente cobre o território continental e se detém ao limite legal marítimo, não obstante, as empresas e os governos precisam de dados e/ou informação referidas aos direitos, restrições e responsabilidades também no ambiente marinho. Na América do Sul a administração destes interesses não foi ainda unificada ou padronizada, muito menos registrada em um sistema de informação geográfica de referência único oficial nacional. Neste contexto, o objetivo deste estudo é contribuir com a modelagem de um Cadastro Marinho (CM) e desenvolver um protótipo de Sistema de Informação Marinha - SIM para sua implementação, previamente à disponibilização de uma infraestrutura de dados espaciais marinha. O SIM foi desenvolvido sob uma estrutura que responde às necessidades de sistematizar informações para o CM ao vincular os dados temáticos a uma saída gráfica para visualizar dados abertos na Argentina, Brasil e Uruguai. Garante a interoperabilidade a partir do estabelecimento de padrões comuns e pode ser o responsável pelo cadastro e pelas atividades de monitoramento do ambiente marinho. Foi construído em JavaScript, com o auxílio de bibliotecas open source como a LeafletJS e suas extensões. Os resultados deste trabalho dão diretrizes para o estabelecimento do marco legal relevante associado a este empreendimento no que se refere ao delineamento da institucionalidade responsável pela estruturação de um CM sob padrões internacionais.

Palavras-chave: Cadastro Marinho. Sistema de Informação Marinha. Infraestrutura de Dados Espaciais.

\begin{abstract}
The cadastre is the base of a country's territorial administration system, it contains the register of different interests on the national space, it describes the properties geometrically, interoperating with other registries. It usually covers the continental territory and remains within the legal maritime limit, however, companies and governments need information regarding rights, restrictions and responsibilities also in the marine environment and in its coastal zone. In South America, the administration of these interests has not yet been unified or standardized, much less registered in a geographic information system. In this context, the objective of this study is to contribute to a Marine Cadastre modeling and to develop a prototype of a Marine Information System for its implementation, prior to the availability of a marine spatial data infrastructure. The system was developed under a structure that responds to the needs to systematize information for this type of registration by connecting thematic data to a graphic output to view open data in Argentina, Brazil and Uruguay. It guarantees interoperability based on the establishment of common standards and could be responsible for the registration and monitoring activities of the marine environment. It was built in JavaScript language (JS), with specific open source libraries for Web Maps, among which are TurfJS, LeafletJS and some specific plugins. The results of this work provide guidelines to establish a relevant legal framework with regard to the design of the institutional structure responsible for a Marine Cadastre under international standards. Keywords: Marine Cadastre. Marine Information System. Spatial Data Infrastructure.
\end{abstract}




\section{INTRODUÇÃO}

Este estudo tem como objetivo contribuir com a modelagem de um Cadastro Marinho (CM) e desenvolver um protótipo para sua implementação, de modo a fortalecer o planejamento e a administração do litoral do Atlântico Sul correspondente a Argentina, Brasil e Uruguai. Os objetivos específicos consistem em descrever um marco conceitual amplo, identificar e propor conceitos de parcela e objeto territorial marinho que possam ser adaptados aos marcos jurídicos dos países e identificar os atores essenciais e membros potenciais relevantes para a conformação de Comitês de Cadastro Marinho em cada jurisdição e a nível internacional.

Esta pesquisa estabeleceu duas hipóteses complementares e sequenciais para a estruturação de um CM. A primeira afirma que é possível compatibilizar os marcos conceitual e regulatório referidos a caraterização física e ambiental da costa atlântica da América do Sul atendendo as regulações específicas dos países analisados: Argentina, Uruguai e Brasil. A segunda, que a informação geoespacial disponível em cada país pode ser compilada e gerida através de um Sistema de Informação Marinha integrado e estruturado através de uma plataforma de acesso livre.

Tomando como base a estrutura de componentes do CM (Figura 2), a investigação analisou os marcos conceituais no nível internacional e delineou conceitos para Parcela e Objetos Territoriais Legais Marinhos (OTLM), os quais podem ser adaptados aos marcos jurídicos dos países. De forma a dar materialidade aos conceitos delineados, desenvolveu-se um protótipo de um Sistema de Informação Marinha (SIM), baseado em informações disponíveis nas instituições com jurisdição nas costas dos países em estudo.

Os resultados deste trabalho lançam as bases organizacionais e geotecnológicas, e fornecem diretrizes para o estabelecimento do marco legal relevante para este empreendimento, principalmente no que se refere ao delineamento da institucionalidade responsável pela estruturação de um cadastro marinho coordenado entre a Argentina, o Brasil e o Uruguai, interoperável sob padrões internacionais. Discorre acerca das experiências atuais de planejamento integrado territorial-marinho-costeiro, e também sobre estratégias, métodos e recursos necessários à manutenção de um cadastro de ambiente marinho, estabelecendo estratégias para a interoperabilidade institucional e das Infraestruturas de Dados Espaciais - IDE nacionais dos litorais dos países.

Foram identificados diversos dados abertos úteis para a estruturação dos bancos de dados do Sistema de Informação Marinha - SIM, os quais respondem às necessidades de orientar a produção de informações específicas para esse tipo de cadastro. A interoperabilidade está garantida porque os dados foram ligados a uma saída gráfica que permite visualizar os dados disponíveis nos três países.

O SIM proposto envolve a natureza e as relações espaciais dos OTLM no que tange aos interesses, direitos e limitações à propriedade na jurisdição marítima. Este sistema é apropriado para o cadastro e para as atividades de monitoramento constante do ambiente marinho. Neste sentido, entende-se que os resultados técnicos alcançados reafirmam que a estruturação do CM internacional é viável e pode fazer parte de uma Política Pública Nacional nos três países.

\section{REVISÃO BIBLIOGRÁFICA}

Atendendo aos objetivos específicos, procedeu-se a uma revisão do estado da arte no que se refere a conceitos, iniciativas internacionais, estruturação de dados e componentes de cadastros marinhos no mundo.

\subsection{Conceitos relacionados com o Cadastro Marinho}

O cadastro territorial é uma componente fundamental do sistema de administração de terras de um país. Contêm o registro dos distintos interesses sobre o território e dados básicos relacionados aos aspectos econômico, físico e jurídico (LOCH; ERBA, 2007, p. 15-16), os quais têm se tornado imprescindíveis, mas insuficientes para a gestão.

O modelo de cadastro territorial multifinalitário (CTM), com origem na Europa após a segunda guerra mundial, aterrissou na América Latina no final do século passado e se dissemina no mundo de forma crescente, 
ainda que não uniformemente. Este modelo ampliou o número de variáveis territoriais registradas na base de dados, sendo adotado atualmente por diversas jurisdições, inspiradas na eficiência deste instrumento, na definição de políticas públicas orientadas a melhorar o planejamento e no financiamento municipal com pequenos investimentos. Atualmente na região existe uma visão generalizada que aponta para a necessidade de sistemas de informação territorial mais amplos e multifinalitários, como ferramentas fundamentais para realizar planejamentos abrangentes nos níveis nacional, regional e local. A estrutura modular destes sistemas permite interconectar o cadastro básico com os cadastros temáticos, ou seja, os sistemas continuam sendo baseados em parcelas, mas incluem dados sobre meio ambiente, infraestrutura, equipamento urbano, instalações e realidade socioeconômica dos habitantes, sendo mantidos por diferentes órgãos públicos ou empresas privadas (ERBA; PIUMETTO, 2016).

As legislações nacionais e locais relacionadas ao cadastro na América Latina incorporaram termos como multifinalidade, infraestrutura de dados espaciais (IDE) e georreferenciamento, porém, na prática, percebe-se que sua implementação é lenta. As administrações agregam aspectos multitemáticos em diferentes ritmos, o que é perfeitamente válido, uma vez que o cadastro multifinalitário é modular, não excludente e não tem uma forma única de ser estruturado. Este é um dos pontos fortes do modelo CTM, que se estrutura como complementar ao cadastro básico (ERBA, 2015).

Normalmente o cadastro cobre o território continental e se estende até o limite legal marítimo estabelecido nas jurisdições. Não obstante, as empresas e os governos precisam de dados e informações referidas aos direitos, restrições e responsabilidades (DRR) também no ambiente marinho, especialmente na sua zona costeira. Neste sentido, ao ampliar o espaço geográfico novas temáticas se fazem presentes sendo necessário incluir os objetos que conformam o CM para fundamentar sua definição.

Vários conceitos para o Cadastro Marinho (CM) surgiram durante as últimas décadas. Um dos primeiros foi proposto por Robertson et al. (1999). Os autores afirmam que se trata de um sistema que registra os limites que definem física e espacialmente os direitos e interesses marinhos e sua relação com outros direitos e interesses vizinhos, acima e abaixo da superfície.

Pouco depois, Todd (2001) amplia a visão afirmando que o CM descreve a localização e a extensão espacial dos DRR nesse ambiente, incluindo o manejo dos planos de desenvolvimento costeiro, as áreas e os limites legalmente estabelecidos. Oferece aos usuários e partes interessadas a possibilidade de descrever, visualizar espacialmente e conhecer a informação do ambiente marinho.

Nichols et al. (2006), em uma visão sistêmica, definem o CM como um sistema de informação que registra, administra e visualiza os interesses e os dados espaciais (parcelas) e não espaciais (informação descritiva sobre a situação legal, as partes interessadas, os recursos naturais, entre outras) que o compõem. Neste sentido, um CM poderia registrar e controlar os diferentes direitos e licenças outorgadas em áreas marinhas, tomando como base o entorno ecológico e o zoneamento definido a partir dos planos especiais para o ambiente marinho, nos casos em que existam.

Athanasiou et al. (2017) ampliam ainda mais a visão ao afirmar que o CM é um dos componentes fundamentais que integram um Sistema de Administração Marinha - MAS (por sua sigla em inglês Marine Administration System). Associando o CM às Infraestruturas de Dados Espaciais Marinhos - IDEM e às políticas de planejamento espacial marítimo, se estabelecem relações sinérgicas que permitem configurar um MAS de maneira integrada.

De acordo com Florentino et al. (2019) as IDEM seguem em franco desenvolvimento por diversos países. Casos como da Alemanha (SEIP; BILL, 2016; MDI-DE, 2018), Dinamarca (HARTMANN, 2015; IHO, 2019b), Canadá (NRCAN, 2018), Croácia (TAVRA; LEDER; CETL, 2018), Malásia (MyGDI, 2018), Singapura (CHEN, 2019) e Brasil (DHN, 2018; 2021), demonstram a pujança das IDEM que se mostram em diferentes níveis de maturidade de implementação ou operação. Tais iniciativas são apoiadas pela Organização Hidrográfica Internacional - IHO (por sua sigla em inglês International Hydrographic Organization) (MARATOS, 2006; IHO, 2017a; 2017b) em conjunto de outras instituições e projetos governamentais (UNGGIM WGMGI, 2019; INSPIRE, 2018) e não-governamentais (IHO, 2019a; SMART OCEANS, 2018).

No ambiente marinho, a identificação espacial e o sistema de informação devem ser mais flexíveis técnica, jurídica e administrativamente do que o cadastro da terra, posto que vários interesses marinhos não têm uma posição geográfica fixa, não podem ser demarcados no local, têm extensões volumétricas (se 
dependem de profundidade, por exemplo), entre outras variantes que dificultam o seu registro. As oportunidades estão relacionadas a licenças ou a possibilidade de ser proprietário de uma embarcação com licença para uso, entre outros. Na Argentina, Brasil e Uruguai, a administração desses interesses não se encontra unificada nem ainda padronizada, muito menos registrada em uma base de dados com estrutura geográfica única, tampouco existe um sistema de informação que faça interoperar as partes. As frequentes alterações de legislação e normativas sobre o uso e ocupação do espaço marinho, no entanto, apontam para a necessidade de implementação de um sistema de informação que venha a possibilitar o planejamento e a gestão deste espaço. Verifica-se, cada vez mais frequente, descobertas de novas fontes de riquezas minerais e espaços com potencialidades para o uso racional do ambiente marinho, aliado com ao aumento natural da demanda pelos usos tradicionais (navegação, pesca, lazer e outros). Nesse contexto, há necessidade de um sistema cadastral que dê publicidade a estes diversos usos, possibilitando assim a execução de um Planejamento do Espaço Marinho (PEM) que aponte ao uso sustentável deste ambiente a longo prazo.

\subsection{Iniciativas internacionais para a estruturação do Cadastro Marinho}

Como mencionado anteriormente, o conjunto de instituições que conformam o sistema de administração de terras normalmente abarcam somente o território continental, não avançam para além do limite legal marinho, mesmo quando um país necessita de uma estrutura administrativa integral que considere os direitos, restrições e responsabilidades, tanto na parte continental como no ambiente marinho e zona costeira.

Esta necessidade já foi reconhecida no âmbito internacional pelo comitê permanente sobre Sistema de Informação Geográfica (SIG) para Ásia e Pacífico (PCGIAP) durante o Congresso para Administração do Ambiente Marinho, ocorrido na Malásia em 2014, e endossado pela Organização das Nações Unidas (ONU) por meio da resolução da $17^{\text {a }}$ Conferência para Ásia e o Pacífico (UNRCC-AP) no ano de 2006 em Bangkok, Tailândia. Os avanços científicos e tecnológicos já apresentam bases sólidas para viabilizar a implementação do CM.

Collier et al. (2003) informam que o Sistema de Gerenciamento Marítimo da Austrália costumava regular algumas atividades relacionadas aos setores de petróleo e gás, pesca, aquicultura, transporte, conservação, patrimônio marinho, cabos e tubulações e zona costeira. Esta iniciativa demonstrava já no início do século a relevância de um CM para qualificar a administração do ambiente marinho.

Constata-se que na última década vários países com extensa faixa litorânea e grandes espaços marinhos, sobre os quais exercem soberania e poderes administrativos, têm mostrado interesse em implementar os conceitos relacionados com o Modelo de Domínio de Administração Marinha (Marine Administration Domain Model), porém, ainda falta um padrão comum e um modelo base aceitos para gerir especificamente os DRR e suas extensões espaciais.

Austrália, Canadá, Países Baixos e Estados Unidos desenvolveram sistemas para administração de interesses marinhos e gestão sustentável dos recursos marinhos (ATHANASIOU et al. 2015). Seus esforços relacionam-se ao desenvolvimento conceitual e sistemático do CM, a IDEM e ao planejamento espacial marinho.

As fronteiras marítimas compartilham um elemento comum com suas contrapartes terrestres pois, para o mapeamento é preciso interpretar adequadamente a lei e seu contexto espacial. As fronteiras marítimas são delimitadas, mas não demarcadas e, geralmente, não há evidências físicas delas (ASTOR et al., 2017). No entanto, muito progresso tem sido feito na implementação de sistemas de navegação inteligente que incorporam fronteiras, limites, rotas e outros elementos marítimos abstratos (AIS, RIS, etc.).

Os conceitos e estruturas de dados propostos pelos diferentes países permitem gerar um diagrama conceitual voltado a materializar uma interpretação gráfica do CM. Como mostra a Figura 1, há uma série de conceitos envolvidos em um cadastro marinho. 


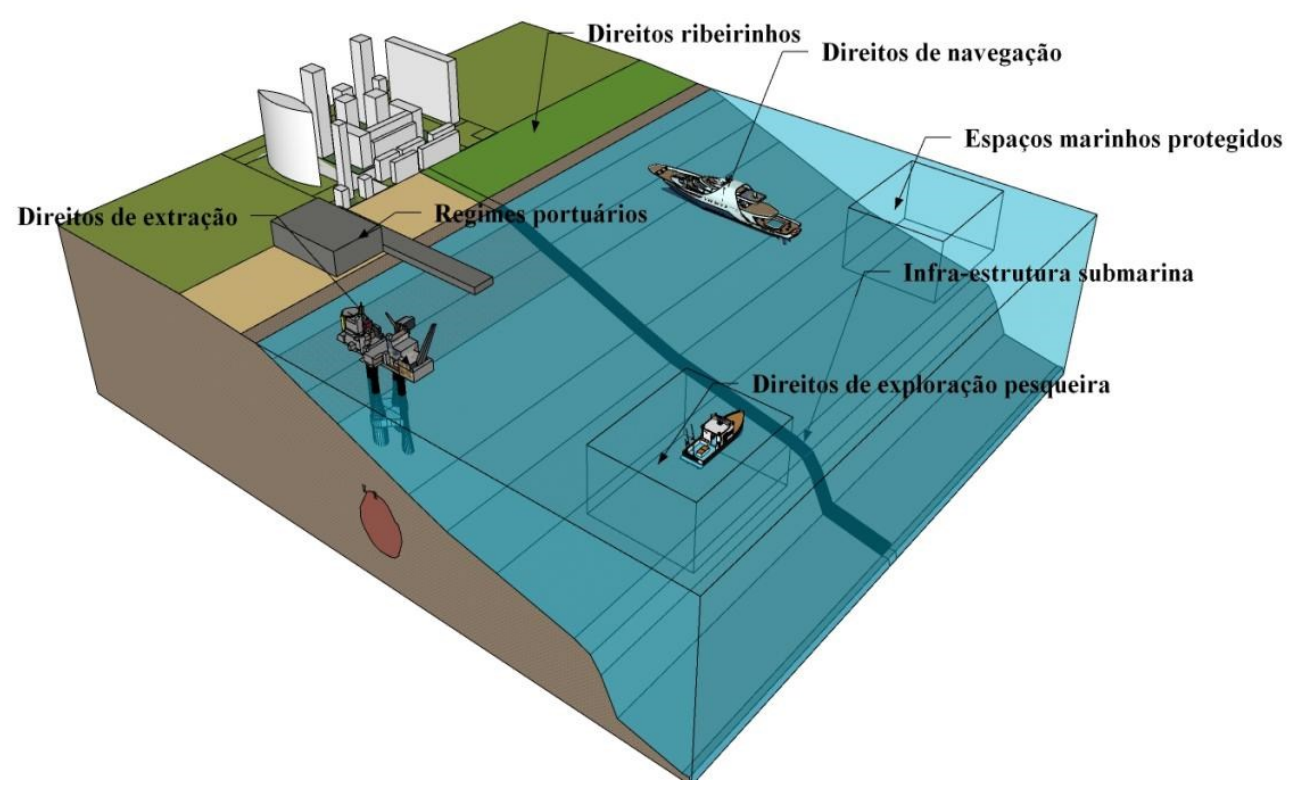

Fonte: Adaptada de Abdullah et al. (2013, p. 26)

\subsection{Componentes do Cadastro Marinho}

O CM tem em sua estrutura vários componentes, elementos e atores com diferentes funções e envolvidos de diferentes formas. A Figura 2 apresenta os componentes mais importantes por meio de um esquema geral (os números entre parênteses correspondem aos itens em que os componentes são descritos neste trabalho).

Para administrar a diversidade e a quantidade de componentes de um CM que estabeleça as relações interinstitucionais e otimize a gestão do ambiente marinho faz-se necessário estabelecer um Sistema de Informação Marinho (SIM). Em face a esta necessidade, desenvolveu-se um protótipo para avaliar os meios e possibilidades de implementação, de modo a contribuir com as instituições que administram o ambiente marinho.

\subsubsection{NORMAS NACIONAIS E INTERNACIONAIS RELACIONADAS AO AMBIENTE MARINHO}

No Brasil, a Constituição Federal prevê, em seu artigo 20, que são bens da União, entre outros, o mar territorial e os recursos naturais da plataforma continental e da zona econômica exclusiva. A Secretaria de Coordenação e Governança do Patrimônio da União (SPU) é a instituição responsável pelo cadastramento dos bens da União, tanto em terra quanto no mar, até o limite do mar territorial. Não existe, no entanto, instituição cadastral específica prevista para atuação junto às outras zonas marítimas, como a Zona Contígua ou a Zona Econômica Exclusiva, o que obrigatoriamente deverá ser definido no marco legal necessário para a implantação de um cadastro marinho no Brasil.

As recentes alterações legais e infralegais em matéria de ocupação do espaço aquático da União apenas mostram que uma legislação específica é necessária. A Portaria $\mathrm{N}^{\circ} 7.145$ do extinto Ministério do Planejamento, Desenvolvimento e Gestão (MPDG), de 13 de julho de 2018, apresenta como objetivo:

Art. $1^{\circ}$ - Estabelecer normas e procedimentos relativos à destinação de terrenos e espaços físicos em águas públicas da União, tais como lagos, rios, correntes d'água e mar territorial, até o limite de 12 milhas marítimas a partir da costa, estabelecida pelo Decreto $n^{\circ} 8.400$, de 4 
de fevereiro de 2015, para a implantação, ampliação, regularização e funcionamento dos portos e das instalações portuárias de que tratam as Leis $\mathrm{n}^{\circ} 12.815$, de 5 de junho de $2013, \mathrm{n}^{\circ}$ 10.233, 5 de junho de 2001 e a Resolução Normativa $n^{\circ} 13$ - Antaq, de 2016, alterada pela Resolução $n^{\circ}$ 5.105-Antaq, de 2016.

Esta portaria trata, entre outras coisas, da reserva de áreas em terras e espaços físicos em águas públicas da União para a instalação de estruturas portuárias, prevendo a emissão pela SPU da certidão de disponibilidade em espaço aquático, instrumento que dá ao interessado a possibilidade de requerer junto ao órgão responsável a concessão de instalação de estruturas portuárias.

Já a Lei No 14.011, de 10 de junho de 2020, altera o artigo 18 da Lei № 9.636, de 15 de maio de 1998, para permitir a dispensa de licitação para cessão de espaço aquático em águas públicas da União para fins de aquicultura, para interessados com projetos aprovados perante a Secretaria de Aquicultura e Pesca do Ministério da Agricultura, Pecuária e Abastecimento, o que visa desburocratizar o processo de concessão.

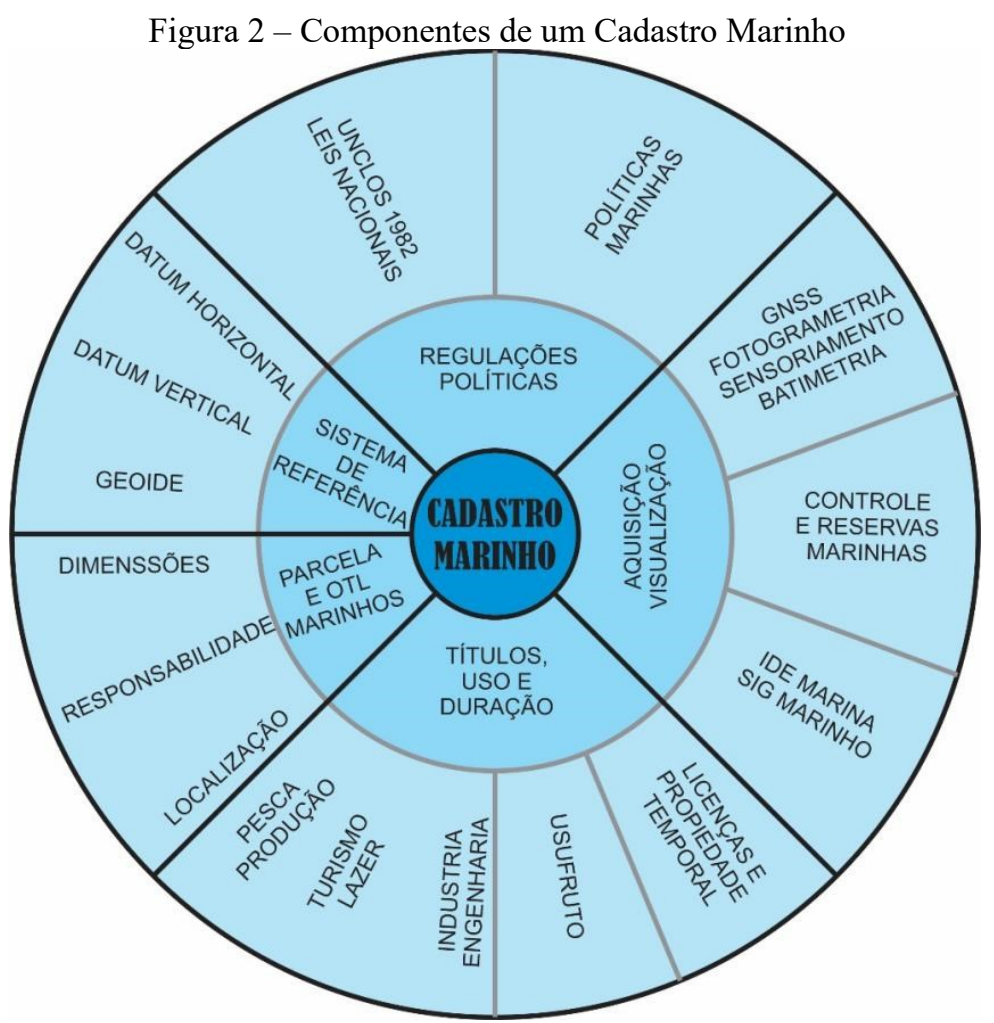

Fonte: Adaptada de Abadullah et al. (2014, p. 12)

Na Argentina foi sancionado, em 2015, o Código Civil e Comercial da Nação - CCyCN, que é a normativa federal mais importante após a Constituição Nacional.

No art. 235 o CCyCN estabelece que forma parte do domínio público o mar territorial, a Zona Econômica Exclusiva (ZEE) e a plataforma continental, compreendida pela água, o leito e o subsolo, verticalmente superpostos. Relacionado ao mar, também são de domínio público as baías, golfos, enseadas, portos, ancoradouros, praias e ilhas que se formem dentro de seus limites. Adicionalmente, o mesmo artigo define o espaço aéreo sobre o mar territorial como outro elemento de domínio público.

Quanto ao limite jurídico que separa o continente do mar territorial, o CCyCN somente o estabelece para as praias, definindo-o com base no alcance das "mais altas marés normais".

A Lei Nacional Argentina $\mathrm{N}^{\mathrm{0}} 24.922$, do regime federal de pesca, reconhece às províncias os direitos de exploração somente dentro do mar territorial, ou seja, até 12 milhas marítimas.

A informação geográfica que materializa limites no ambiente marinho foi abordada em diversas publicações. Em 2009, com a apresentação inicial perante a Comissão de Limites da Plataforma Continental da ONU, sendo finalmente aprovada em 2016, e em publicações associadas que foram divulgadas posteriormente a dita aprovação (ex.: COPLA, 2017). Em que pese a componente tridimensional que define o 
espaço marítimo, os limites foram estabelecidos em camadas vetoriais bidimensionais, que são confeccionadas e mantidas pelo Serviço de Hidrografia naval, conforme ditado pela Lei Nacional No 19.922 (Lei Hidrográfica).

O limite entre a costa continental e o início do espaço marítimo configura-se em uma área de faixas contíguas e/ou superpostas, que são definidas pelas províncias com frente para o oceano atlântico, sob critérios próprios. Em geral, estas faixas perseguem os objetivos de proteger o ambiente costeiro e a ocupação ordenada das zonas circunvizinhas. Nesse contexto, ao limite concreto entre o domínio privado das províncias e o domínio público marinho dá-se o nome de Linha de Costa Marítima, e é o limite mais ocidental do espaço marinho argentino.

No Uruguai, o Código Civil incorpora entre os ativos nacionais para uso público os portos, enseadas e costas do território oriental (Art. 478 apartado 2a ). No CAPÍTULO II - Dos Bens em relação as Pessoas, o Art. 479 descreve o uso e gozo que, para trânsito, irrigação, navegação e quaisquer outros objetos lícitos, corresponda aos particulares nas ruas, praças, pontes e vias públicas, no mar e suas margens, nos rios e riachos. Outra caraterística interessante do país, manifesta no Código Civil, é que permite pescar livremente no mar territorial, nos rios e riachos de uso público (Art 713).

\subsubsection{PARCELA MARINHA E OBJETO TERRITORIAL LEGAL MARINHO}

No entorno marinho se deve descrever o recurso, os direitos individuais e o tipo de direito para o uso dos recursos. Além do domínio público no mar territorial, os direitos e seus limites são determinados de acordo com sua destinação (por exemplo: mineração, aquicultura, turismo, navegação, entre outros) e não como propriedade. Em geral, não existe um mercado de parcelas marinhas onde estas se subdividem ou se unifiquem e nem sejam transacionadas.

Uma grande quantidade de trabalhos de investigação e publicações técnico científicas estão se ocupando em delinear uma definição para parcela marinha, sendo que os autores partem basicamente de duas hipóteses:

a) existe uma parcela marinha multidimensional que pode ser considerada como a unidade de referência básica em um CM e;

b) existe uma série de parcelas marinhas (com fins especiais) que podem ser consideradas como unidades de referência básica para coleta, armazenamento e difusão da informação.

Arvanitis et al. (2013 apud ATHANASIOU et al. 2016, p. 95) definem a parcela marinha como "um espaço delimitado que tem especificações comuns, utilizado principalmente como referência para localizar um fenômeno. Uma parcela marinha facilita a distinção entre territórios contíguos e proporciona informação sobre este fenômeno através de uma codificação apropriada".

Nos países sul-americanos o conceito de "parcela" tem implicações jurídicas e cadastrais específicas relacionadas com a regulamentação que lhes dá fundamento (ALBERDI; ERBA, 2020). Embora no direito dos países sul-americanos não possam existir parcelas marinhas no mesmo sentido dado às parcelas terrestres, existem os DRR, cujas definições têm alcances delimitáveis no espaço. Nesse sentido, a parcela marinha tem uma natureza tridimensional, volumétrica, inerente do espaço marinho, e estes poliedros que contêm os DRR são a unidade mínima de administração do CM. Diferentemente das parcelas tradicionais (terrestres), os DRR, como a aquicultura, a mineração, a pesca, o atraque de embarcações e os espaços para navegação; podem coexistir em uma mesma posição, porém em diferentes profundidades.

De um ponto de vista da modelagem administrativa, onde o foco está na abstração do mundo real, o mar não é uma entidade legal até que lhe seja atribuído um interesse. Portanto, a relação estreita entre cada interesse, sua dimensão espacial e evolução no tempo (no mundo real) devem ser identificadas e registradas em sistemas de informação. Estes elementos formam uma entidade única: o objeto territorial legal marinho; de caráter multifinalitário e multidimensional.

Nos oceanos se forma um regime legal diferente, no qual se pode encontrar os seguintes tipos de DRR:

a) Interesses ao nível de Estado: se definem por meio dos tratados internacionais e acordos bilaterais entre estados vizinhos marítimos, os quais se integram com a normativa nacional por meio de leis; 
b) Direitos públicos: referem-se principalmente ao direito constitucional de cada cidadão a ter acesso ilimitado ou sem obstáculos a todo o espaço terrestre e marinho. Estes direitos não estão garantidos para um interesse individual, mas para um interesse público (por exemplo, acesso à praia). Podem descrever-se como protetores do interesse público no uso e conservação dos recursos;

c) Restrições ambientais: referem-se as disposições relacionadas com a proteção e conservação da água, recursos, áreas preservadas e do patrimônio cultural. Estes lugares estão pré-definidos por lei, e os direitos envolvidos são de suma importância e obrigatórios. Os DRR incluem, entre outras, a proteção dos recursos arqueológicos e objetos históricos do mar, a proteção de áreas marinhas preservadas e as restrições em geral;

d) Direitos de uso e exploração: estes tipos de direitos tendem a adquirir natureza privada, associados a indivíduos que coexistem com os direitos públicos. De modo geral, estes termos estabelecem os limites dos direitos, que implicam principalmente nas diferentes formas de uso e gestão, dado que no meio marinho os direitos são limitados em termos de espaço, duração e, o mais importante, a extensão e o conteúdo, e se referem somente aos diferentes tipos de usos. Os interessados não proprietários, são meramente "usuários" beneficiados.

O registro dos DRR definidos em lei se relacionam com a terceira dimensão para a maioria das atividades. Definem em que distância vertical ou horizontal está permitido exercer outros interesses marinhos representados através dos Objetos Territoriais Legais Marinhos (OTLM).

Apesar das evidências, o uso da terceira dimensão, mundialmente, ainda não se consolidou. Os CM incipientes tendem a utilizar a terceira dimensão somente para representação do fundo marinho e do nível do mar, principalmente pela existência de batimetrias do fundo oceânico em escala regional em todo planeta. Adicionalmente, as metodologias de medição e posicionamento precisas dos pontos tridimensionais em relação ao subsolo, leito e nível do mar, facilitam a gestão e o controle dos OTLM. Por sua vez, a natureza multifinalitária do $\mathrm{CM}$ e a forma em que muitas vezes se delimitam os direitos com base em fenômenos ou fatos naturais da paisagem, impõem necessidades adicionais de informação relacionadas ao espaço marinho (geologia, hidrologia, entre outras).

Nas últimas décadas constatou-se que o tempo exerce um papel importante como a quarta dimensão nos sistemas cadastrais, fundamentalmente associada às mudanças de posição ou nos atributos dos DRR. No meio marinho, a maioria das atividades pode coexistir e mover-se no tempo e no espaço e, portanto, o registro da quarta dimensão é fundamental, pois captura a natureza temporal de muitos direitos particulares.

\subsubsection{LIMITES MARINHOS E ZONAS MARINHAS}

Os limites territoriais marinhos são definidos de acordo com a Convenção das Nações Unidas sobre o Direito do Mar - UNCLOS (por suas siglas em inglês United Nations Convention on the Law of the Sea). De acordo com a UNCLOS, zonas distintas são definidas de acordo com o seu status legal, direitos e restrições.

Igualmente a todos os cadastros temáticos propostos, o modelo cadastral deve permitir padrões que garantam compatibilidade, interoperabilidade e acessibilidade aos dados. A norma S-121 da IHO é a base mais importante para o desenvolvimento destes modelos. Este guia propõe um detalhado modelo conceitual de objetos e padrões comuns para a administração ao nível nacional, enquadrando-se no padrão S-100 para dados hidrográficos da IHO. Um dos objetivos destes desenvolvimentos é sustentar com informação geográfica os aspectos legais marinhos, o que permite adaptar-se ou incluir-se dentro de padrões específicos como a ISO19152 do LADM (Land Administration Domain Model).

Athanasiou et al (2017) sugerem que a forma Objeto-Direito-Sujeito que o LADM estabelece como núcleo principal, pode aplicar-se ao território marinho, e sua integração com a série S-100 e S-121 define o marco adequado para descrição dos OTLM.

A IHO de 2018 é uma proposta de padronização da informação geográfica para bases de dados hidrográficos, estruturado mediante gráficos UML (Unified Modeling Language) para a modelagem dos objetos relacionados com estes ambientes. Se enquadra nas normas ISO 19100 e se utiliza como base para o desenvolvimento de sub-padrões. Nesse contexto, está estreitamente alinhado com os preceitos do Open 
Geospatial Consortium (OGC). O Modelo Universal de Dados Hidrográficos da IHO compreende doze partes relacionadas que brindam ao usuário as ferramentas e marco apropriado para desenvolver e manter os dados, produtos e registros relacionados com a hidrografia. Esta série de padrões tem particular relevância, tanto que a hidrografia muitas vezes é compartilhada entre países limítrofes, sobretudo nas frentes marítimas dos continentes. O Quadro 1 mostra as principais especificações.

Quadro 1 - Especificações da IHO.

\begin{tabular}{|c|c|}
\hline Especificações & Nome \\
\hline S-101 & Electronic Navigation Chart \\
S-102 & Bathymetric Surface \\
S-104 & Surface Currents \\
S-111 & Sevel Information for Surface Navigation \\
S-121 & Maritime Limits and Boundaries \\
S-122 & Marine Protected Areas \\
S-123 & Marine Radio Services \\
S-124 & Navigational Warnings \\
S-125 & Marin Navigations Services \\
S-126 & Marin Physical Environment \\
S-127 & Marin Traffic Management \\
S-201 & Aids to Navigation Information \\
& Weather Overlay \\
\hline
\end{tabular}

Fonte: Os autores (2020).

A especificação S-121 é a mais relevante para estruturação de um CM. Suas especificações foram desenhadas com base na primeira parte da norma geral S-100, com o objetivo de propor descrições conceituais que permitem modelar entidades reais (objetos físicos) e abstratas (DRR) - (IHO, 2019a) que constituem os OTL. Seu conteúdo principal oferece uma lista de regras ou requisitos básicos que os objetos ou conjuntos de objetos devem cumprir, que se referem a organização dos dados, a estruturação interna, topologia e geometria que os compõem (descritas em 2D, mas adaptáveis para 3D), junto as distintas versões que podem gerar mudanças no tempo. Se baseia em esquemas UML para representar as relações entre objetos e sujeitos, seguindo a metodologia proposta pelo LADM. Propõe um glossário mínimo de termos comuns e até um teste de validação dos dados. Embora não proponha um catálogo de objetos que compõem o CM, estabelece regras ajustadas às características do espaço marinho, de modo que é necessário validar os conjuntos de dados que colocam à disposição cada país.

As zonas definidas em UN 1997 são as seguintes:

a) O Mar territorial: é a zona situada dentro da faixa de 12 milhas náuticas ( $\mathrm{mn}$ ), onde o estado exerce sua soberania no espaço aéreo, na coluna d'água e no leito marinho e seu subsolo;

b) A Zona contígua: faixa de oceano adjacente ao mar territorial (12 mn), com o limite externo ou a zona contígua que não exceda as 24 milhas náuticas da linha de base mar territorial (LBT);

c) A Zona Econômica Exclusiva: área que se estende desde o limite do mar territorial (12 mn) até as 200 milhas náuticas da LBT, sem excedê-la;

d) A Plataforma Continental: corresponde a superfície de um fundo submarino próximo a costa e com profundidades inferiores a 200 metros. Sua amplitude desde a costa é variável, indo de escassos metros até centenas de quilômetros. A plataforma continental pode estender-se além do limite de 200 mn, até 350 milhas náuticas desde a LBT, sujeita s disposições do Artigo 76 da UNCLOS.

A Figura 3 representa o posicionamento das zonas ao longo de um perfil. 
Figura 3 - Posicionamento as zonas relevantes para o CM.

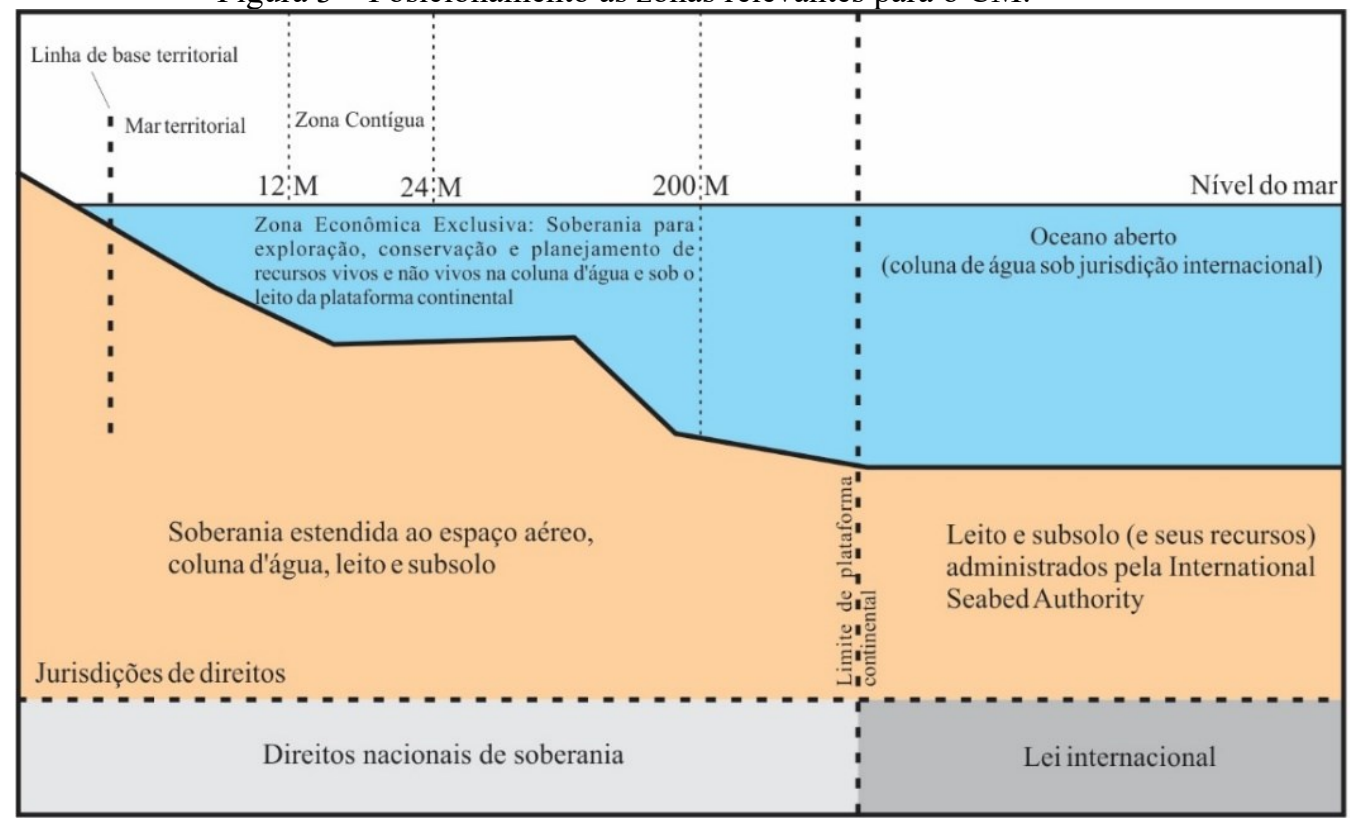

Fonte: Adaptado de Balla e Wouters (2017, p. 9).

\subsubsection{IDERA, INDE, IDEUY}

As IDE tomaram impulso no presente século a partir da incorporação de modelos de gerenciamento público-privados e da incorporação de padrões para interoperabilidade o armazenamento dos dados e seus metadados, estabelecendo políticas cada vez mais claras para a administração do conjunto de atores, dados e tecnologias. Por sua vez, a Infraestrutura de Dados Espaciais Marinhos (IDEM) segue este mesmo preceito, atribuindo destaque ao propósito marítimo relacionando seus respectivos conjuntos de dados em temas ou camadas de interesse à futuras análises (IHO, 2017a).

As infraestruturas nacionais de dados espaciais da Argentina (IDERA), do Brasil (INDE) e do Uruguai (IDEuy) têm evoluído significativamente, e estão suficientemente desenvolvidas para formar parte dos CM dos três países, o qual facilita a sistematização da informação marinha que já compartilham os órgãos nacionais em suas esferas administrativas, passando a compartilhá-la com seus vizinhos. É a forma de gerir uma administração mais holística e competente do espaço marinho e territorial.

A Infraestrutura de Dados Espaciais da República Argentina (IDERA - https://idera.gob.ar/) iniciou suas atividades em 2007, mas formalizou as disposições para conformar uma plataforma de trabalho por meio de uma Ata Acordo somente em 6 de agosto de 2010. No Brasil, a Infraestrutura Nacional de Dados Espaciais (INDE - https://www.inde.gov.br/) foi legalmente instituída pelo Decreto Presidencial No 6.666, de 27 de novembro de 2008. A Infraestrutura de Dados Espaciais do Uruguai (IDEuy https://www.gub.uy/infraestructura-datos-espaciales) foi criada pela Lei No 19.149 de 2013 como um órgão descentralizado da Presidência da república, com autonomia técnica.

IDERA é uma comunidade de informação geoespacial que trabalha em um âmbito colaborativo de caráter nacional e federal, na qual participam os diferentes níveis de governo, a academia e instituições de investigação. A INDE é o conjunto integrado de tecnologias, políticas, mecanismos e procedimentos de coordenação e monitoramento, padrões e acordos, necessários para facilitar e ordenar a geração, o armazenamento, o acesso, o compartilhamento, a disseminação e o uso dos dados geoespaciais de origem federal, estadual, distrital e municipal. A IDEuy visa ordenar a produção e facilitar a disponibilidade, o acesso e uso de produtos, serviços e informação geográfica do território nacional, atualizada e de qualidade, como apoio aos processos de tomada de decisão para o desenvolvimento nacional, inspirando-se nos princípios básicos de cooperação e coordenação entre as administrações, assim como em transparência e o acesso à informação pública.

IDERA tem como objetivo propiciar a publicação de dados, produtos e serviços, de maneira eficiente e oportuna, como um aporte fundamental à democratização do acesso a informação produzida pelo estado e 
diversos atores, bem como apoiar as tomadas de decisões nas diferentes atividades dos âmbitos público, privado, acadêmico, não governamental e da sociedade civil.

A INDE foi concebida com o propósito de catalogar, integrar e harmonizar dados geoespaciais existentes nas instituições do governo brasileiro, produtoras e mantenedoras desse tipo de dado, de maneira que possam ser facilmente localizados, explorados e acessados para os mais diversos usos, por qualquer pessoa que tenha acesso à Internet.

A IDEuy empenha-se em liderar a articulação e o fortalecimento da produção e acesso a informação geográfica do Uruguai, para que seja viável, oportuna, interoperável, de alta qualidade, e dê apoio às análises e as tomadas de decisões de organismos, academia, empresas e cidadãos. Especificamente tem se comprometido em: (i) garantir, através de um conjunto de normas, padrões e recomendações, a interoperabilidade, atualização, qualidade e acesso à informação geográfica nacional; (ii) integrar a informação geográfica pertencente aos diferentes níveis da administração, inspirando-se nos princípios básicos de cooperação e coordenação, assim como a transparência e acesso à informação pública; (iii) constituir o Geoportal com suas linhas básicas de operacionalidade e política de difusão da informação geográfica gerada; e (iv) favorecer a eficiência no gasto público destinado aos distintos aspectos da informação e sistemas de informações geográficas.

\section{O CADASTRO MARINHO NO ATLÂNTICO SUL}

O aperfeiçoamento das IDEs ampliou todas suas componentes, inclusive os limites geográficos de abrangência, os quais atingiram as regiões marinhas. Neste movimento tornou-se necessário integrar as informações espaciais por meio do acesso e compartilhamento de dados costeiros e marinhos. A Figura 4 esquematiza a interrelação IDE-IDEM-SIT-SIM.

São necessárias, no entanto, instituições que possibilitem a estruturação do cadastro marinho de uma maneira imparcial. Atualmente não há, por exemplo, no Brasil ou na Argentina sistema que dê publicidade à extensão espacial dos direitos no ambiente marinho. Neste ambiente, conforme mencionado anteriormente, é comum a coexistência de direitos múltiplos numa mesma área. No entanto, algumas atividades ainda são impossíveis de conciliar. Assim, no intervalo de tempo entre a formalização da cessão de uma área e a efetiva materialização de um empreendimento, pode-se incorrer na cessão da mesma área (ou parte dela) a outro interessado, a exemplo do que ocorre em terra devido aos antigos sistemas cadastrais alfanuméricos.

Figura 4 - Combinação entre os sistemas de gerenciamento terrestre e marinho.

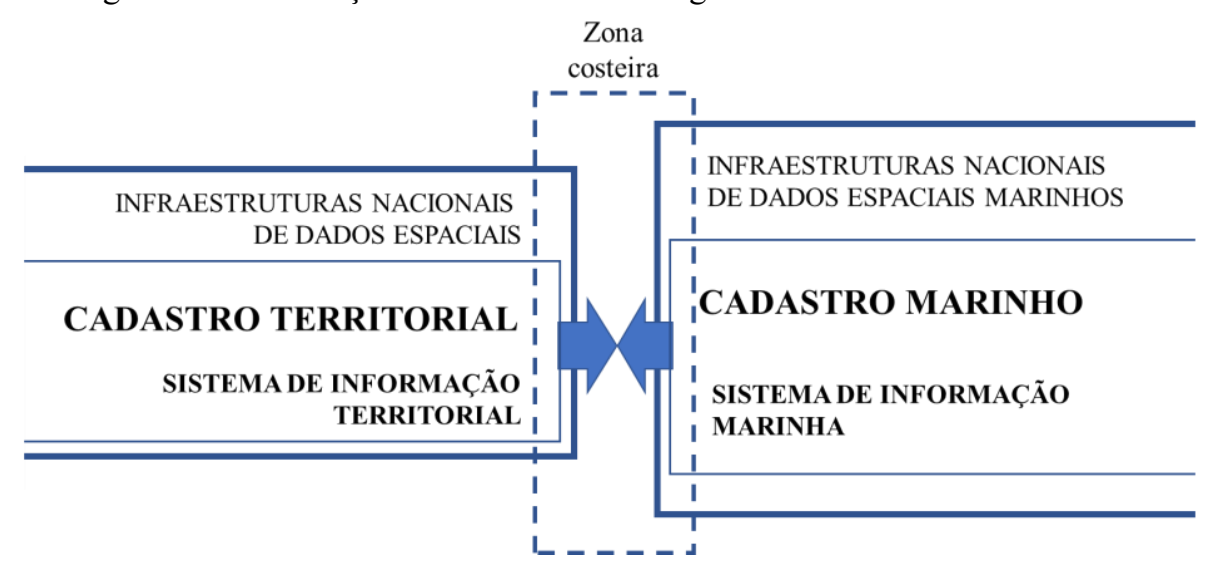

Fonte: Adaptado de Strain, Rajabifard e Williamson (2006, p. 439).

A tendência é que os setores busquem facilitar, por meio da promoção de mudanças legais e infralegais, a cessão de direitos no espaço marinho a seu favor. Sem um sistema cadastral que possibilite, por um lado, a administração destes direitos e, por outro, o planejamento pelas autoridades das áreas mais propícias para cada atividade, a tendência é que haverá a ocupação desordenada do espaço marítimo, o que se traduzirá em problemas para todos os envolvidos e para o meio-ambiente em geral.

É necessária uma legislação única, válida para todos os setores interessados no uso e exploração do 
ambiente marinho, que preveja a declaração da disponibilidade e a eventual reserva das áreas por parte do órgão cadastral antes da efetiva concessão da exploração das mesmas pelos poderes concedentes.

\subsection{Sistema de Informação Marinha - SIM}

Inspirado em sistemas de cadastro marinho de outros países se implementou um Sistema de Informações Marinhas por meio de um Web Mapa 2D em código aberto (open source). A opção pela bidimensionalidade se deu por diversos motivos, entre os quais, elencamos ${ }^{1}$ :

a) A vasta disponibilidade de dados em duas dimensões na zona costeira, em mar e terra, de interesse para o planejamento marinho já atualmente disponíveis;

b) A praticamente inexistência de dados geográficos em três dimensões disponíveis e

c) A inexistência de infraestrutura adequada para o armazenamento de dados em três dimensões.

Neste contexto, ante a disponibilidade de dados essenciais para o CM em duas dimensões e atendendo ao que ocorre no CM em outros países, optou-se pela implantação de uma plataforma 2D.

A opção pela utilização do ambiente web se deu pela facilidade de acesso aos mapas, haja vista que, uma vez disponibilizado neste ambiente, os Web Mapas podem ser acessados de qualquer localidade, em qualquer estação de trabalho, independentemente do sistema operacional e com a mínima necessidade de hardware, sendo necessário tão somente a utilização de um navegador moderno para o seu acesso.

O SIM foi construído em linguagem JavaScript (JS), com o auxílio de bibliotecas open source específicas para a Web Mapas 2D, entre as quais se encontram LeafletJS, TurfJS e algumas extensões (plugins) específicas. A Figura 5 ilustra suas principais funcionalidades WebGIS. Deve-se notar que o sistema é facilmente extensível, o que é imperioso neste momento do desenvolvimento, já que num futuro próximo deve ser implementada uma infraestrutura de dados espaciais marinhos (IDEM), cujos dados também deverão ser passíveis de visualização. A ligação da IDEM ao SIM está prevista, portanto, e está representada na Figura 5 por linhas tracejadas.

Os principais dados atualmente disponíveis são provenientes das bases de dados do Instituto Brasileiro de Geografia e Estatística (IBGE), do Instituto Geográfico Nacional (IGN) da Argentina e do Instituto Geográfico Militar (IGM) do Uruguai. Também foram utilizados dados comuns aos três países, como a batimetria e o índice de topônimos da General Bathymetric Chart of the Oceans (GEBCO, 2019) recomendada pela IHO como dado de referência para os demais elementos geográficos (IHO, 2017a). Todos estes dados foram obtidos a partir dos geoserviços WMS (Web Map Services) e WFS (Web Feature Services) conectados diretamente aos bancos de dados geográficos destes institutos. Dados complementares, ainda não disponíveis por geoserviços, foram obtidos e adicionados à repositórios hospedados no Projeto Cadastro-Marinho no Github (https://github.com/Cadastro-Marinho), tais como as poligonais dos portos brasileiros, muitas das quais foram recentemente revisadas pelo Ministério da Infraestrutura. Estes repositórios foram criados como alternativa ao necessário Nó Central do projeto, infraestrutura que deverá ser obrigatoriamente disponibilizada no futuro àquelas instituições públicas ou privadas que aderirem ao projeto, porém não estejam dispostas a manter uma estrutura própria.Também neste projeto encontra-se o código do visualizador.

\subsubsection{SISTEMA DE REFERÊNCIA}

A princípio, em busca de eficiência computacional, julgou-se conveniente para o SIM a adoção do sistema de referência espacial (SRS) Web Mercator (EPSG: 3857), que se tornou o padrão para os WebGIS desde a implementação do Google Earth (BATTERSBY et al., 2014, p. 92). Para a maioria das aplicações, a projeção Web Mercator é conveniente, ainda que esta seja uma projeção ligeiramente não-conforme, i.e. as distorções angulares são mínimas (BATTERSBY et al., 2014, p. 89). Para alguns usos, no entanto, como a navegação, pode ser desejável a aplicação de uma projeção conforme. A eventual adoção de diferentes SRS que venham a se mostrar adequados no futuro, no entanto, não é uma limitação do SIM, mas função apenas da

\footnotetext{
${ }^{1}$ Atualmente já encontram-se disponíveis diversas bibliotecas open source para o desenvolvimento de API's (Interface de Programação de Aplicativos) para Web Mapas 3D, entre os quais se destacam wrld.js e CesiumJS (um uso pode ser visto em https://www.ngdc.noaa.gov/gazetteer/), de maneira que não elencamos qualquer entrave tecnológico para este tipo de implementação.
} 
disponibilidade de servidores de imagens nestes sistemas de referência.

\subsection{Níveis de dados essenciais do Cadastro Marinho}

Conforme Strain, Rajabifard e Williamson (2006), os dados espaciais marinhos que adquiriram maior relevância passaram a constituir as IDEM, devendo ser organizados em camadas referentes as fronteiras, áreas de proteção ambiental, rotas de navegação e infraestrutura portuária, climatologia e meteorologia, regime de marés, ondas e correntes, recursos vivos e não vivos, composição do fundo e sub-fundo, além de outras questões legais nacionais e internacionais. Essa mesma linha foi seguida para a estruturação das camadas do SIM.

Por dados Espaciais entende-se o conjunto de elementos: limites marítimos, áreas de conservação e preservação, habitats marinhos, oceanografia, batimetria, hidrografia, geologia, infraestrutura marítima, localização de naufrágios, instalações offshore, tubulações e cabos submarinos, e outros (IHO, 2017a).

Figura 5 - Diagrama UML do SIM.

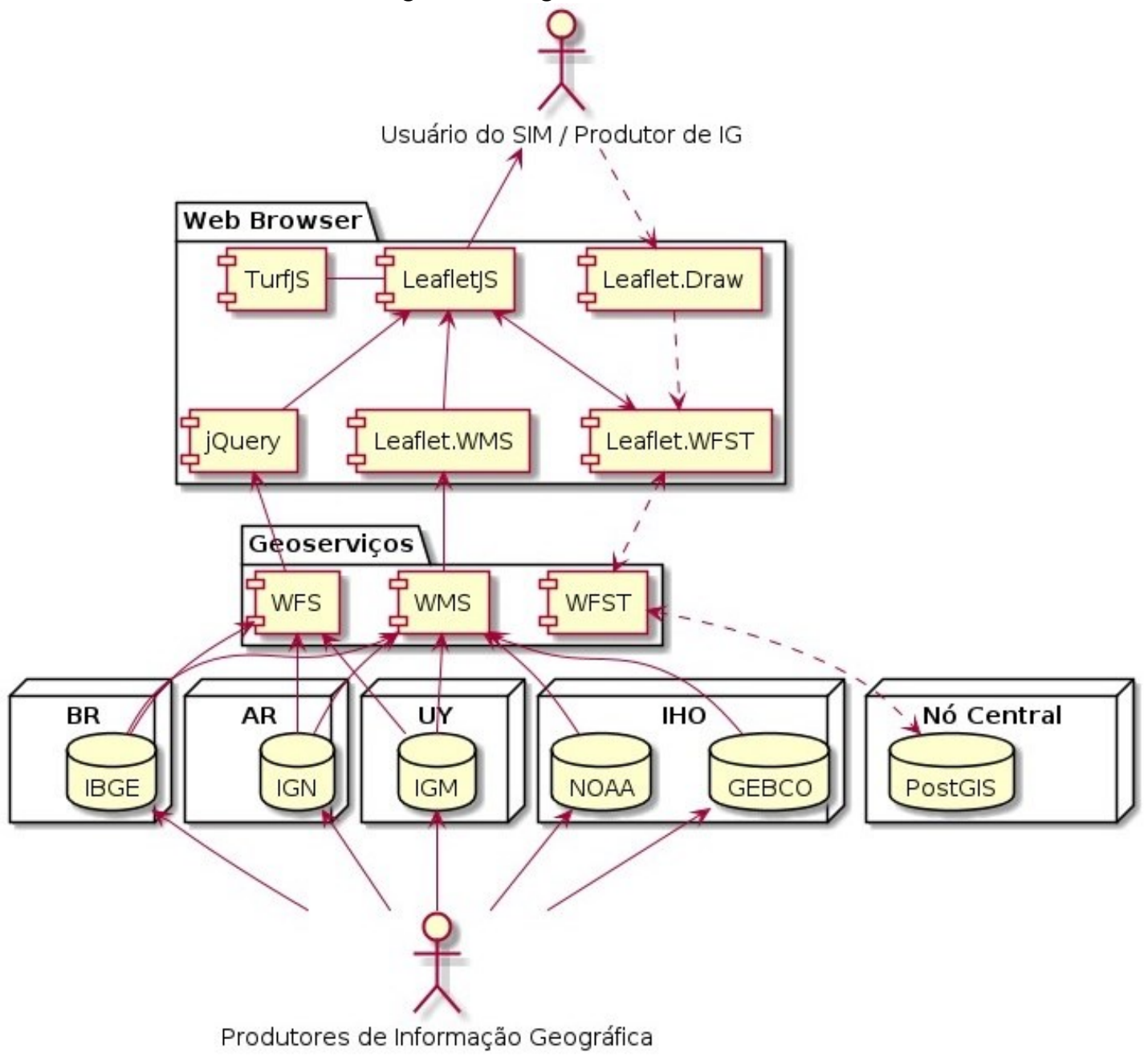

Fonte: Os autores (2020).

Consultando as IDE dos 3 países do Atlântico Sul da América do Sul foram selecionadas as camadas jurídicas essenciais (fronteiras), bem como exemplos de camadas temáticas sugeridas Strain et al (2006) e a Figura 2. As camadas essenciais estão relacionadas no Quadro 2. 
Quadro 2-Camadas essenciais e temáticas do CM em cada país

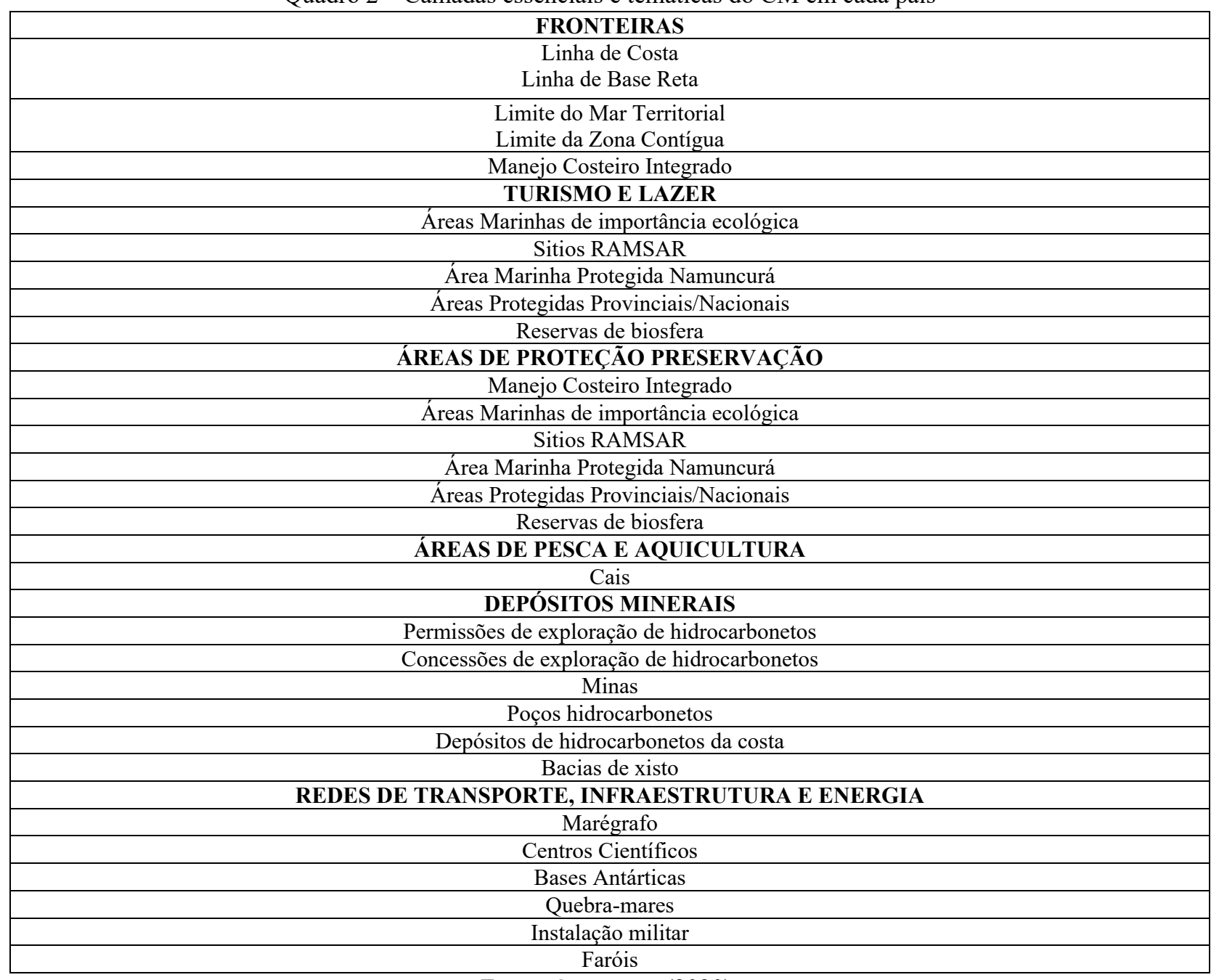

Fonte: Os autores (2020).

\subsection{Atores relevantes e membros potenciais do Cadastro Marinho}

Contar com uma ferramenta tecnológica como o SIM que permite integrar os dados já disponíveis e identificar as informações que ainda devem ser sistematizadas é fundamental para estruturar um cadastro marinho internacional. Outro passo neste sentido é identificar os atores relevantes e membros potenciais pois serão os responsáveis por levar adiante a política de complementação, integração e interoperação.

O Quadro 3 apresenta uma lista não exaustiva, mas orientativa, dos atores de nível alto e intermédio de governo, instituições científicas, acadêmicas e agências com protagonismo e responsabilidades na estruturação e manutenção do cadastro marinho para o Atlântico Sul.

\subsection{Integração IDEM - CM - SIM}

A Organização Hidrográfica Internacional fundamenta uma IDEM em quatro colunas: política e governança (pessoas), especificações técnicas (padrões), conteúdo geográfico (dados espaciais) e sistemas de informação (tecnologias), sendo esta último pilar a motivação para o desenvolvimento do Sistema de Informação Marinha como componente tecnológica do CM.

O CM é uma ferramenta de administração pública e privada projetada para prover dados e informações necessárias para o planejamento e para o auxílio ao processo de tomada de decisão. Destina-se a proporcionar segurança jurídica ao planejamento do desenvolvimento do espaço marítimo, os direitos, os arrendamentos e o acesso aos mares. O CM apresenta diferenças significativas em relação ao cadastro territorial: as técnicas convencionais de demarcação e subdivisão tradicionais do cadastro territorial não se aplicam ao CM, ao tempo que a coexistência de múltiplos direitos ao longo do espaço é sua caraterística mais comum. 
Quadro 3- Atores relevantes.

\begin{tabular}{|c|}
\hline Ministério da Agricultura, Pecuária, Pesca e Abastecimento (MAPA) \\
Ministério do Meio Ambiente (MMA) \\
\hline Ministério do Desenvolvimento Regional (MDR) \\
Ministério do Turismo \\
\hline Secretaria de Coordenação e Governança do Patrimônio da União (SCGPU) \\
\hline Instituto Nacional de Pesquisas Espaciais (INPE) \\
\hline Conselho Nacional de Desenvolvimento Científico e Tecnológico (CNPq) \\
\hline Instituto Brasileiro de Geografia e Estatística (IBGE) \\
\hline Secretaria de Pesca e Aquicultura \\
\hline Agência Nacional de Águas (ANA) \\
\hline Agência Nacional de Transportes Aquaviários (ANTAQ) \\
\hline Serviço Geológico do Brasil (CPRM) \\
\hline Marinha do Brasil \\
\hline Agência Nacional de Mineração (ANM) \\
\hline Agência Nacional do Petróleo (ANP) \\
\hline Instituto Brasileiro de Direito do Mar (IBDMAR) \\
\hline Universidades Federais (principalmente as localizadas na costa atlântica) \\
\hline Fonte: Os autor (2020).
\end{tabular}

Fonte: Os autores (2020).

O SIM viabiliza a interoperabilidade das camadas correspondentes ao relevo do leito do mar, a geologia, a infraestrutura marinha, a utilização de recursos, os limites administrativos e legais, áreas de conservação, habitats e oceanografia disponibilizadas pelas IDE dos diferentes países, outros geoserviços e pelo CM em ambiente próprio.

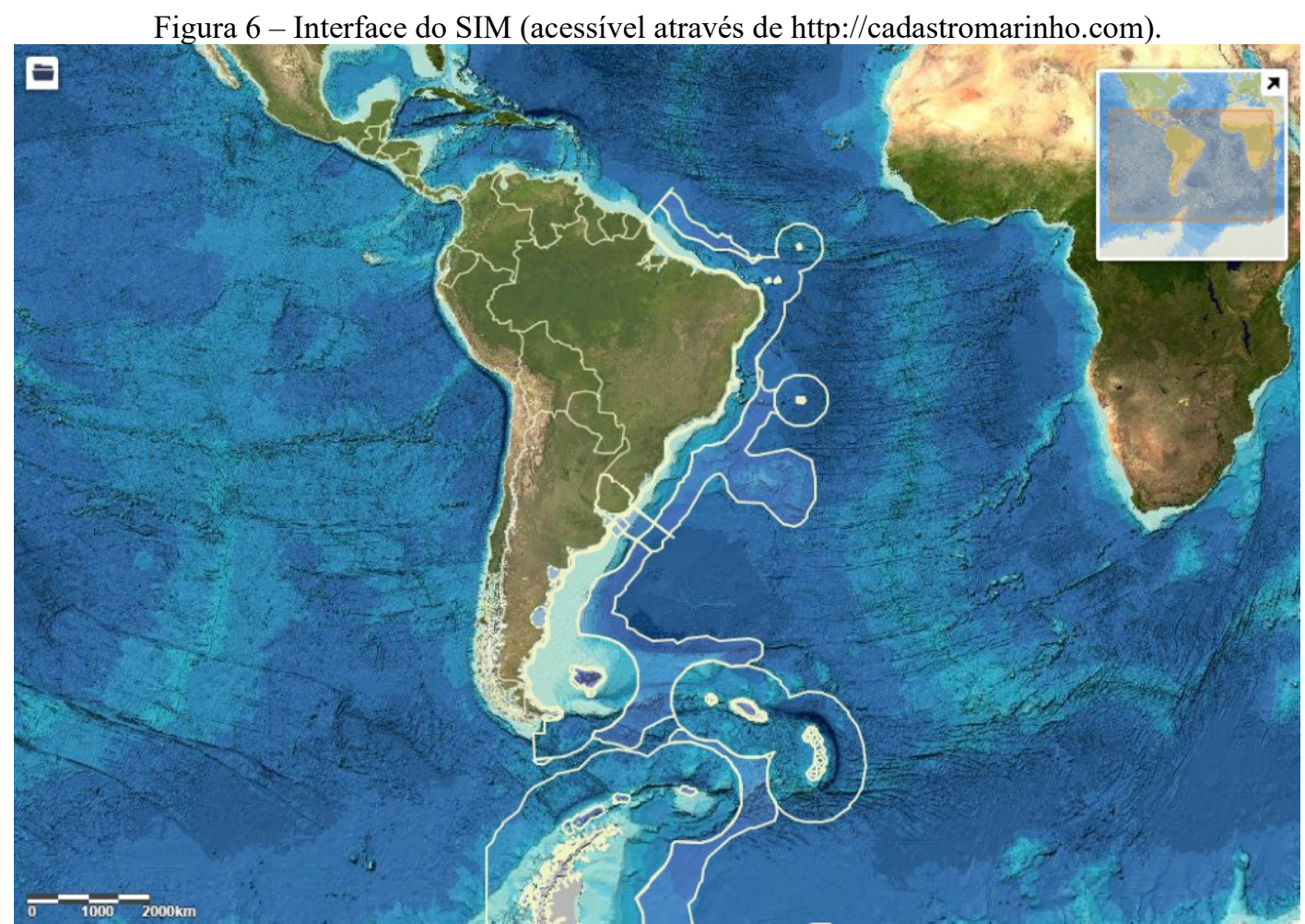

Fonte: Os autores (2020).

O conjunto IDEM, CM e SIM se constitui na fonte de dados subjacentes mais importantes para permitir a implementação do planejamento espacial marinho, uma vez que este processo requer o conhecimento dos limites e das informações relacionadas ao ambiente marinho. As Figuras 6 e 7 apresentam a tela inicial do SIM e algumas das suas funcionalidades podem ser visualizadas as fronteiras legais mais relevantes, como os limites da extensão da plataforma continental pleiteados por Brasil e Argentina, sobre um mapa de base conveniente, disponibilizado pela GEBCO/IHO. Ainda é possível alternar de forma simples entre uma gama de camadas 
adicionais tornadas disponíveis, como dados sobre nomes de regiões marinhas, batimetria e outros.

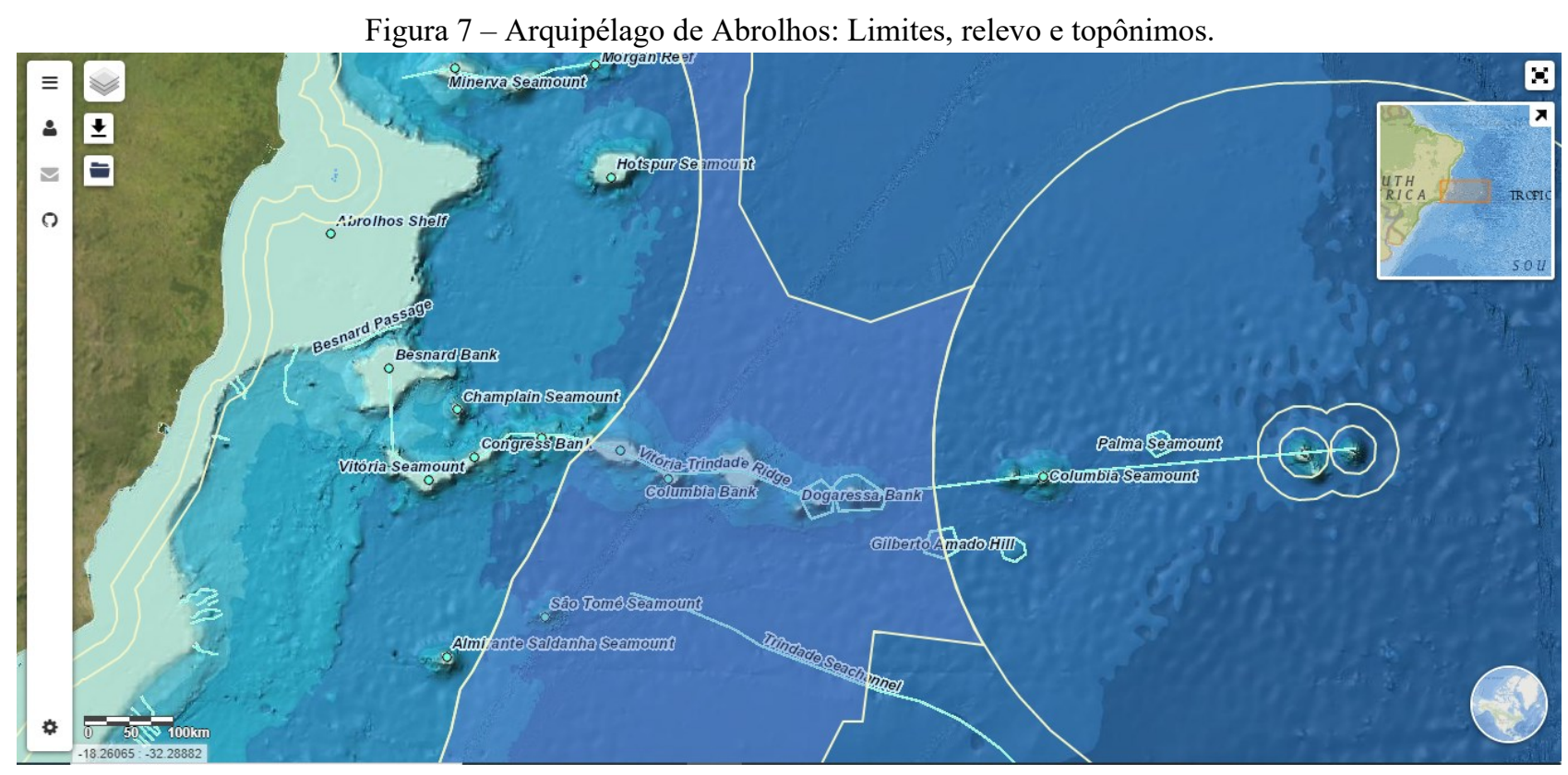

Fonte: Os autores (2020).

\section{CONCLUSÃO}

O ambiente marinho é essencial para o bem estar da população mundial e, como tal, deve ser utilizado de modo equilibrado para assegurar a sustentabilidade. Neste sentido, é importante que as informações relacionadas a interface das populações com o ambiente marinho estejam sistematizadas e controladas, de modo a contribuir para o uso adequado dos espaços em que as atividades humanas se desenvolvem, de modo especial na zona costeira, onde ações antrópicas ocorrem de maneira mais intensa.

Neste viés, o trabalho apresenta um caminho para a sistematização das informações, baseado em plataformas tecnológicas livres, em que as definições de um cadastro territorial (parcelas e objetos territoriais legais) foram adaptadas para o ambiente marinho seguindo as diretrizes internacionais. Todo o potencial de benefícios que um cadastro oferece ao evidenciar e controlar direitos, restrições e responsabilidades, estão presentes nesta proposta e podem (devem) contribuir para a sustentabilidade.

Ao analisar as legislações dos países em estudo, pôde-se identificar os principais atores e membros potenciais para o estabelecimento do cadastro marinho, bem como os acessos às bases de dados existentes que possibilitaram modelar conceitualmente e mostrar que o desenvolvimento do protótipo do sistema de informação marinha em ambiente web é possível, previamente à existência de infraestrutura própria para o armazenamento de dados marinhos.

O sistema e a estratégia desenvolvidos permitem conviver com as diferenças no que tange a disponibilidade temática e nível de detalhamento, extraindo o mais relevante de cada IDE e dados abertos existentes em cada país, incentivando a disponibilização de dados eventualmente existentes ainda previamente à constituição da IDEM.

Para concretizar esta proposta vai ser fundamental que se estabeleça um marco legal de institucionalização do cadastro marinho no Atlântico Sul. O fórum apropriado para que isto se estabeleça, naturalmente, deverá ser o MERCOSUL, a mais abrangente iniciativa de integração regional da América Latina. Este marco legal deverá prever também a disponibilização de uma infraestrutura mínima para que as instituições responsáveis possam tornar públicas as informações geográficas no ambiente marinho, dar publicidade aos seus atos e conferir aos diversos atores públicos e privados meios para um uso racional deste ambiente, o que deverá ser feito por meio de um planejamento espacial marinho.

Enquanto a definição e a extensão espacial de uma parcela marinha ou OTLM não se materializa, o importante é poder afirmar que ela existe e ter claro que facilita a distinção entre territórios contíguos, 
proporcionando informação sobre este fenômeno por meio de uma codificação apropriada.

A consolidação do relacionamento das IDE nacionais com o SIM dar-se-á por meio de um desenvolvimento harmônico, i.e. gradativamente, respeitando as necessidades e limitações orçamentárias e tecnológicas de cada país. Esta integração age também como um dispositivo de conexão internacional e demonstra que é possível reforçar os valores nacionais e internacionais de transparência e participação do Estado junto à sociedade em prol do bem comum.

A médio prazo, em publicações posteriores, espera-se sistematizar de forma mais ampla o marco jurídico relevante para este empreendimento, bem como delinear a institucionalidade e apresentar as experiências atuais de planejamento integrado territorial-marinho-costeiro, descrevendo estratégias, métodos e recursos necessários para o estabelecimento e manutenção de um cadastro do ambiente marinho, entrelaçar o tecido social, as redes de cooperação interinstitucional para estabelecer novos parâmetros de governança como impulsores do desenvolvimento das diferentes regiões marinho-costeiras e estabelecer estratégias para o desenho, implementação e administração de uma infraestrutura de dados espaciais dos litorais dos países.

Quanto ao SIM, espera-se que o seu desenvolvimento seja contínuo e se dê de maneira comunitária. Por este motivo a modelagem foi estritamente baseada em software livre. Espera-se que este trabalho seminal incentive a comunidade de pesquisadores, profissionais e entusiastas do cadastro marinho a colaborar com o projeto. Com o engajamento de profissionais habilitados o desenvolvimento deve se dar de maneira exponencial.

\section{Contribuição dos Autores}

Luiz Fernando Palin Droubi: Conceptualização, Análise Formal, Metodologia, Software, Redação minuta inicial e Redaçao - revisão e edição. Diego Erba: Conceptualização, Análise Formal, Metodologia, Redação - minuta inicia e Redaçao - revisão e edição. Ramiro Alberdi: Conceptualização, Análise Formal, Metodologia, Redação - minuta inicial e Redaçao - revisão e edição. Everton Silva: Conceptualização, AnáliseFormal, Redaçao - revisão e edição.

\section{Conflitos de Interesse}

Os autores declaram que não há conflitos de interesse.

\section{Referências}

ABDULlAH, A.; AROF, Z.M.; TAJAM, J. Marine Cadastre Issue and Conceptual for Implementation in Malaysia. Jurnal Intelek (2013) Vol 8(1), p. 24-30.

ABDULlAH, A., OMAR, A. H.; CHAN, K. L; MAT AROF, Z.; JAMIL, H.; TENG, C. H. The Development of Marine Cadastre Conceptual Model for Malaysia. In: FIG Congress, XXV, 2014, Kuala Lumpur, Malaysia. Online Proceedings... Disponível em: http://www.fig.net/resources/proceedings/fig_proceedings/fig2014/papers/ts11j/TS11J_abdullah_omar_e t_al_6866.pdf. Acesso em: 20 set. 2021.

ALBERDI, R.; ERBA, D. A. Modeling Legal Land Object for waterbodies in the context of 4D cadastre. Land Use Policy,Elsevier, vol. 98(C). 2020. DOI. 10.1016/j.landusepol.2019.104417

ARVANITIS, A. Development of an integrated geographical information system for the marine space. Athens: Hellenic Cadastre. 2013.

ASTOR, Y; SULASDI, W. N.; HENDRIATININGSIH, S; WISAYANTONO, D. The Evaluation of Marine Cadastre Definitions Among Australia, Canada and United States of America Based on Indonesia's Perspective as an Archipelagic State. In: YOMRALIOGLU, T.; MCLAUGHLIN, J. (Ed.). Cadastre: 
Geo-Information Innovations in Land Aministration. Cham, Switzerland: Springer; New Dheli, India: Capital Publishing Company. 2017. pp. 275-308.

ATHANASIOU, A.; DIMOPOULOU, E.; KASTRISIOS, C.; TSOULOS, L. Management of Marine Rights, Restrictions and Responsabilities according to International Standards. In: $5^{\text {th }}$ International FIG 3D Cadastre Workshop, 2016. Athens, Greece. Online Proceedings... Disponível em: http://www.gdmc.nl/3DCadastres/literature/3Dcad_2016_15.pdf. Acesso em: 20 set. 2021.

ATHANASIOU, A.; PISPIDIKIS, I.; DIMOPOULOU, E. 3D Marine Administration System Based on LADM. In: Abdul-Rahman, A. (Ed.) Advances in 3D Geoinformation. Lecture Notes in Geoinformation and Cartography. Springer, Cham. DOI: 10.1007/978-3-319-25691-7_22.

ATHANASIOU, A.; SUTHERLAND, M.; KASTRISIOS, C.; TSOULOS, L.; GRIFFITH-CHARLES, C.; DAVIS, D.; DIMOPOULOU, E. Toward the Development of a Marine Administration System based on International Standards. ISPRS International Journal of Geo-Information. Vol. 6. No. 194. MDPI. 2017.

BALLA, E.; WOUTERS, R. Marine Cadastre in Europe: State of Play (Nr. 355). In: WORLD BANK. RESPONSIBLE Land Governance: Towards and Evidence Based Approach. Washington DC: [s.n.], mar. 2017.

BATTERSBY, S.; FINN, M.; USERY, E.; YAMAMOTO, K. Implications of Web Mercator and Its Use in Online Mapping. Cartographica: The International Journal for Geographic Information and Geovisualization. 49. 85-101. 10.3138/carto.49.2.2313. 2014.

CHEN, J. Singapore's National Marine Spatial Data Infrastructure (NMSDI) Concept: GeoSpace-Sea. 2019. Disponível em: https://portal.ogc.org/files/?artifact_id=83030. Acesso em: 20 set. 2021.

COPLA, Comisión Nacional del Límite Exterior de la Plataforma Continental. El margen continental argentino. Entre los $35^{\circ}$ y $55^{\circ}$ de latitud Sur en el contexto del artículo 76 de la Convención de las Naciones Unidas sobre el Derecho del Mar. Buenos Aires, Argentina. Ministerio de Relaciones Exteriores y Culto. 2017.

COllier, P.; LEAHY, F. J.; WILliAMSON, L. P. Defining A Marine Cadastre For Australia. In: $42^{\text {nd }}$ Australian Surveyors Congress, 2001, Brisbane, Australia. Disponível em: http://hdl.handle.net/11343/33895. Acesso em: 20 set. 2021.

DHN, Diretoria de Hidrografia e Navegação. Portaria n 13, de 19 de fevereiro de 2018, da DHN. Aprova a Norma de Acesso aos Dados e às Informações Abertas da Diretoria de Hidrografia e Navegação (NAD-DHN). 2018. Disponível em: https://www.marinha.mil.br/dhn/?q=pt-br/nad. Acesso em: 20 set. 2021.

DHN, Diretoria de Hidrografia e Navegação. MSDI-WG National Report (BRAZIL). Tóquio, Japão. IHOMSDIWG 2021. Disponível em: https://iho.int/uploads/user/InterRegional\%20Coordination/MSDIWG/MSDIWG12on/MSDIWG12on-04C_National_Report_Brazil.pdf. Acesso em: 20 set. 2021.

ERBA, D. A. El Catastro Territorial Multifinalitario y el Desarrollo Urbano. Cuadernos Urbanos, cuaderno No. 3. Quito, Ecuador. Ministerio de Desarrollo Urbano y Vivienda de Ecuador. 2015.

ERBA, D. A.; PIUMETTO, M. A. Para leer el suelo urbano: Catastros multifinalitarios para la planificación y el desarrollo de las ciudades de América Latina. Lincoln Institute of Land Policy. Cambridge, MA. Estados Unidos. 2016.

FLORENTINO, C.; BRAVO PIMENTEL, V.; NETO, A. A. Desenvolvimento e Perspectivas da Infraestrutura de Dados Espaciais Marinhos Brasileira. Revista Brasileira de Cartografia. Vol. 71, n. 3, julho/setembro, 2019. pp. 619-646.

GEBCO. General Bathymetric Chart of the Oceans. Disponível em: https://www.gebco.net/ . Acesso em: 20 set. 2020.

HARTMANN, J. P. W. National Approach in Data Exchange - Danish Maritime Spatial Data Infrastructure. 2nd Baltic Forum of MSP. 2015. Disponível em: 
$<$ http://www.balticscope.eu/content/uploads/2015/07/W2_7_presentation_3_Jens_Peter_W.Hartmann.pdf $>$. Acessado em abril de 2019. IHO, 2017a.

IHO, International Hydrographic Organization. White Paper - Realising the benefits of Spatial Data Infrastructures in the Hydrographic Community. 2017b. Disponível em: https://iho.int/mtg_docs/com_wg/MSDIWG/MSDIWG9/MSDIWG9-05H-MSDIWG_submission_to_C1.pdf. Acesso em: 20 set. 2021.

IHO, International Hydrographic Organization. IHO-MSDIWG: Marine Spatial Data Infrastructure Working Group. 2019a. Disponível em: https://iho.int/en/basic-msdiwg-documents. Acesso em: 20 set. 2021.

IHO, International Hydrographic Organization. IHO-MSDIWG. Business Case for a Further Development of the Danish Marine Spatial Data Infrastructure (MSDI). 2019b. Disponível em: https://iho.int/en/msdiwg10-2019. Acesso em: 20 set. 2021.

INSPIRE, Infrastructure for Spatial Information in the European Community. Geoportal. Disponível em: http://inspire.jrc.ec.europa.eu. Acesso em: 20 set.2021.

LOH, C.; ERBA, D. Cadastro Técnico Multifinalitário Rural e Urbano. Lincoln Institute of Land Policy. Cambridge, MA. 2007.

MARATOS, A. The Role of Hydrographic Services with Regard to Geospatial Data and Planning Infrastructure. International Hydrographic Review, v. 7, n. 2, p. 51-53, 2006.

MDI-DE - Marine Dateninfrastruktur Deutschland. Geoportal. Site $<$ https:// www.mdi-de.org>.

NICHOLS, S.; NG'ANG'A, S. M.; SUTHERLAND, M. D.; COCKBURN, S. Marine Cadastre Concept. In: CALDERBANK, B.; MACLEOD, A. M.; MCDORMAN, T. L.; GRAY, D. L. (Ed.). Canada's Offshore: Jurisdiction, Rights and Management. $3^{\text {rd }}$ Ed. Victoria, Canada. Trafford Publishing. 2006.

NRCAN, Ministery of Natural Resources Canada. GeoConnections. 2018. Disponível em: https://www.nrcan.gc.ca/science-and-data/science-and-research/earth-sciences/geomatics/canadasspatial-data-infrastructure/10783. Acesso em: 20 set. 2021.

ROBERTSON, B; BenWell, G.; HOOGSTEDEn, C. The Marine Resource: Administration Infrastructure Requirements. In: UN-FIG Conference on Land Tenure and Cadastral Infrastructures for Sustainable Development. 1999, Melbourne, Australia. Online Proceedings... Disponível em: https://www.fig.net/resources/proceedings/1999/figun/sessions/session6/robertson.pdf. Acesso em: 20 set. 2021.

SEIP, C.; BILL, R. A Framework for the Evaluation of Marine Spatial Data Infrastructures - Accompanied by International Case-Studies. GeoScience Engineering, v. 62, n. 2, p. 27-43, 2016. DOI: 10.1515/gse-20160015

SMART OCEANS. Smart Oceans 2020. 2020. Disponível em: https://www.smartoceans2020.org/. Acesso em: 20 set. 2021.

STRAIN, L. M.; RAJABIFARD, A.; WILLIAMSON, I. Marine administration and spatial data infrastructure. Marine Policy, v. 30, n. 4, p. 431-441, 2006.

TAVRA, M.; LEDER, T. D.; CETL, V. Stakeholders Needs Requisite Analysis: Towards Croatian Marine Spatial Data Infrastructure Establishment. Tehnicki vjesnik - Technical Gazette. v. 25, p. 176-182, 2018. Site https://doi.org/10.17559/TV-20160607222834>.

TODD, P. Marine cadastre. Opportunities and implications for Queensland. In: Institute of Australian Surveyors Annual Conference, 2001, Brisbane, Australia. Online Proceedings... Disponível em: https://citeseerx.ist.psu.edu/viewdoc/download?doi=10.1.1.197.3068\&rep=rep1\&type=pdf. Acesso em: 20 set. 2021.

UN-GGIM WGMGI, United Nations Committee of Experts on Global Geospatial Information Management Working Group on Marine Geospatial Information. Summary Report of First Expert Meeting of the WGMGI. Busan, Coréia do Sul, março de 2019. Disponível em: http:/ggim.un.org/meetings/2019/WGMGI-Busan. 


\section{Biografia do autor principal}

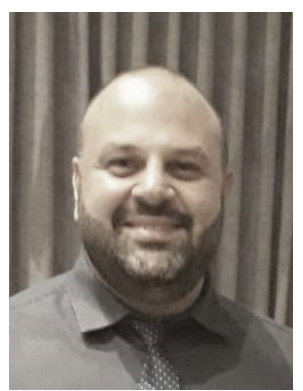

Luiz F. P. Droubi é engenheiro civil formado pela Universidade de São Paulo (2003); especializado em Auditoria, Avaliações e Perícias de Engenharia pelo IPOG (2016); Cientista de Dados pela Datacamp (2017). Atualmente é mestrando no Programa de Pós-Graduação em Engenharia de Transportes e Gestão Territorial da UFSC. Faz parte do quadro de engenheiros da Empresa Brasileira de Infraestrutura Aeroportuária, encontrando-se atualmente cedido à Secretaria de Coordenação e Governança do Patrimônio da União em Florianópolis/SC. devido crédito pela criação original. 